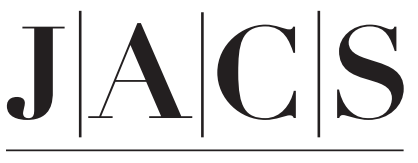

A R T I C L E S

Published on Web 02/16/2006

\title{
Zeolite Framework Stabilized Copper Complex Inspired by the 2-His-1-carboxylate Facial Triad Motif Yielding Oxidation Catalysts
}

\author{
Kaisa Kervinen, ${ }^{\dagger}$ Pieter C. A. Bruijnincx ${ }^{\ddagger}$ Andrew M. Beale,${ }^{\dagger} J$. Gerbrand Mesu, ${ }^{\dagger}$ \\ Gerard van Koten, ${ }^{\ddagger}$ Robertus J. M. Klein Gebbink, ${ }^{\ddagger}$ and Bert M. Weckhuysen*, ${ }^{\star}$ \\ Contribution from the Department of Inorganic Chemistry and Catalysis, Utrecht University, \\ Debye Institute, Sorbonnelaan 16, 3584 CA Utrecht, The Netherlands, and Department of \\ Organic Chemistry and Catalysis, Utrecht University, Debye Institute, Padualaan 8 , \\ $3584 \mathrm{CH}$, Utrecht, The Netherlands
}

Received October 13, 2005; E-mail: b.m.weckhuysen@chem.uu.nl

\begin{abstract}
The stabilization of a mononuclear copper(II) complex with one $\mathrm{MIm}_{2} \mathrm{Pr}$ ligand $\left[\mathrm{MIm}_{2} \mathrm{Pr}=3\right.$,3bis(1-methylimidazol-2-yl)propionate] in the supercages of zeolite $Y$ was attempted, and the resulting materials were tested for their activity in oxidation catalysis. The preparation procedure yielded initially two species (labeled 1 and 2 ) within the pore system of the zeolite material, which differ in molecular structure and chemical composition as determined by UV/vis, ESR, IR, and XAFS spectroscopy. In species 1, the copper was found to be five-coordinated, with one $\mathrm{MIm}_{2} \mathrm{Pr}$ ligand in a facial-type NNO coordination toward copper, the other two coordination sites being occupied by oxygen atoms from either the zeolite framework and/or a water molecule. The total charge of this complex is $1+$. In species 2 , the copper is surrounded by two $\mathrm{Mlm}_{2} \mathrm{Pr}$ ligands, both in a facial-type coordination mode, identical to the homogeneous $\mathrm{Cu}\left(\mathrm{MIm}{ }_{2} \mathrm{Pr}\right)_{2}$ complex. This neutral species $\mathbf{2}$ is easily washed out of the zeolite, whereas the mononuclear species 1 remains inside the zeolite material upon washing. The spectroscopic characteristics and activity for 3,5di-tert-butylcatechol and benzyl alcohol oxidation of species 1 compared closely with that of the zeoliteimmobilized $\mathrm{Cu}$ (histidine) complexes but differed from that of the homogeneous $\mathrm{Cu}\left(\mathrm{MIm}_{2} \mathrm{Pr}\right)_{2}$ complex. It was therefore found that encapsulation in zeolite offers a route to stabilize a 5 -fold-coordinated copper complex with novel catalytic properties. This $1: 1 \mathrm{Cu}\left(\mathrm{MIm}_{2} \mathrm{Pr}\right)$ complex is not formed in solution.
\end{abstract}

\section{Introduction}

Oxidation of organic substances is one of the most important methods for producing diverse functionalized chemicals from oil derivatives and biofeed materials. ${ }^{1,2}$ In the production of fine chemicals, it is imperative that reactions are selective. In nature, enzymes can perform selective oxidation reactions at mild conditions. ${ }^{3,4}$ Therefore, it is very attractive to design catalysts which closely mimic the active sites of enzymes. ${ }^{5-9}$

Recently, a group of mononuclear non-heme iron(II) enzymes has emerged, which share a common structural motif. This motif is called the 2-His-1-carboxylate facial triad, consisting of two

\footnotetext{
$\dagger$ Department of Inorganic Chemistry and Catalysis.

Department of Organic Chemistry and Catalysis.

(1) Skibida, P.; Sakharov, A. M. Catal. Today 1996, 27, 187-193.

(2) Ebner, J.; Riley, D. Active Oxygen in Chemistry; Chapman and Hall: London, 1995.

(3) Lippard, S.; Berg, J. Principles of Bioinorganic Chemistry; University Science Books: Sausalito, CA, 1994.

(4) Kaim, W.; Schwederski, B. Bioinorganic Chemistry: Inorganic Elements in the Chemistry of Life; John Wiley \& Sons: New York, 1994

(5) Wang, Y.; DuBois, J. L.; Hedman, B.; Hodgson, K. O.; Stack, T. D. P. Science 1998, 279, 537-540.

(6) Rohde, J.-U.; In, J.-H.; Lim, M. H.; Brennessel, W. W.; Bukowski, M. R.; Stubna, A.; Münck, E.; Nam, W.; Que, L., Jr. Science 2003, 299, $1037-$ 1039.

(7) Yoon, S.; Lippard, S. J. J. Am. Chem. Soc. 2005, 127, 8386-8397.

(8) Aboelella, N. W.; et al. J. Am. Chem. Soc. 2004, 126, 16896-16911.

(9) Holm, R. H.; Solomon E. I. Chem. Rev. 2004, 104, 347-1200.
}

histidine ligands and one carboxylate group occupying one face of an octahedron around the central divalent metal ion. The sites on the other face of the octahedron are either vacant or occupied by weakly coordinating ligands (Figure 1a). ${ }^{10,11} \mathrm{~A}$ remarkably wide assortment of oxidative transformations is catalyzed by this family of enzymes, ranging from the cis-dihydroxylation of arene double bonds to heterocyclic ring formation. The triad thus serves as a versatile platform for the activation of dioxygen. ${ }^{10,11}$ In recent years, models have been reported for the different kinds of reactivity displayed by the different enzyme classes exhibiting the 2-His-1-carboxylate facial triad. ${ }^{12-16}$ Although very accurate functional models have been constructed, the all $N$-donor ligands usually employed do not accurately mimic the $N, N, O$ donor set found at the active site.

(10) Costas, M.; Mehn, M. P.; Jensen, M. P.; Que, L. Jr. Chem. Rev. 2004 104, 939-986.

(11) Koehntop, K. D.; Emerson, J. P.; Que, L. Jr. J. Biol. Inorg. Chem. 2005 10, 87-93.

(12) Jo, D.-H.; Que, L., Jr. Angew. Chem., Int. Ed. 2000, 39, 4284-4287.

(13) Chen, K.; Costas, M.; Kim, J.; Tipton, A. K.; Que, L., Jr. J. Am. Chem. Soc. 2002, 124, 3026-3035.

(14) Jensen, M. P.; Lange, S. J.; Mehn, M. P.; Que, E. L.; Que, L., Jr. J. Am. Chem. Soc. 2003, 125, 2113-2128.

(15) Mehn, M. P.; Fujisawa, K.; Hegg, E. L.; Que, L., Jr. J. Am. Chem. Soc. 2003, 125, 7828-7842.

(16) Ogihara, T.; Hikichi, S.; Akita, M.; Moro-oka, Y. Inorg. Chem. 1998, 37, 2614-2615.

10.1021/ja0567992 CCC: $\$ 33.50$ @ 2006 American Chemical Society 


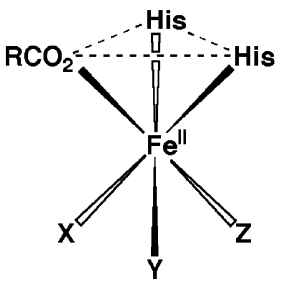

(a)

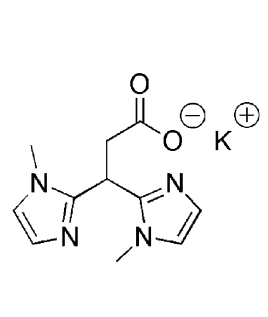

(b)

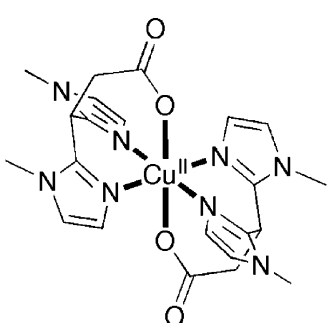

(c)

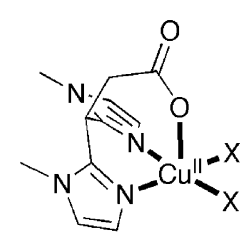

(d)

Figure 1. Research strategy to create an artificial $\mathrm{Cu}(\mathrm{II})-2$-His-1-carboxylate facial triad: (a) structure of the facial triad $(\mathrm{X}, \mathrm{Y}, \mathrm{Z}=$ weakly coordinated ligands, such as water molecules); (b) newly synthesized $\mathrm{NNO}$-ligand $\left(\mathrm{MIm}_{2} \mathrm{Pr}\right)$; (c) coordination around the metal in the homogeneous 1:2 complex; and (d) a schematic drawing of the complex inside the zeolite $\mathrm{Y}$ pore $(\mathrm{X}=$ zeolite framework oxygen).

To structurally mimic the 2-His-1-carboxylate facial triad more closely, we recently reported the synthesis of a new ligand $\left(\mathrm{MIm}_{2} \mathrm{Pr}\right)$, which provides an $\mathrm{N}, \mathrm{N}, \mathrm{O}$ donor set incorporating a carboxylate group (Figure 1b). Using $\mathrm{Cu}(\mathrm{II})$ as a probe, we studied the coordination chemistry of this new ligand and found that the complexation of this ligand with half an equivalent of a $\mathrm{Cu}(\mathrm{II})$ salt resulted in a centrosymmetrical 1:2 complex with the ligand facially capping the copper atom (Figure 1c). ${ }^{17}$ The formation of mononuclear complexes with one ligand coordinated, however, proved troublesome. The reaction with 1 equiv of copper(II) precursor yields structures of higher nuclearity; for example, $\mathrm{Cu}(\mathrm{OTf})_{2}(\mathrm{OTf}=$ trifluoromethanesulfonate $)$ forms dinuclear complexes with the $\mathrm{MIm}_{2} \operatorname{Pr}$ ligand. ${ }^{18}$ However, to mimic the coordination environment around the metal in 2-His1-carboxylate-type enzymes, a mononuclear complex should be formed with only one $\mathrm{MIm}_{2} \mathrm{Pr}$ ligand coordinated to the metal and the other sites occupied by weakly coordinating ligands. So far, this has been difficult to achieve in a homogeneous system.

Therefore, we decided to investigate the possibility of stabilizing the mononuclear complex inside a microporous zeolitic support, such as zeolite Y (Figure 1d). Specifically, our rationale for using this zeolite was to make use of the $13 \AA$ pores of zeolite $Y$ to prevent the dimerization of the complex and to stabilize it using the oxygens from the zeolite framework to occupy the newly created free coordination sites around copper, thus providing an anchoring site in the zeolite. In addition, there also exists the consideration that the zeolite support could influence the properties of the immobilized complex. By changing the properties of the zeolite material, also the properties of the immobilized complex can be influenced.

Indeed, similar approaches have been used before, and as such, there exists several examples on the successful immobilization of transition metal complexes inside zeolite supercages. ${ }^{19-35}$ In most cases, the aim is to improve the

(17) Bruijnincx, P. C. A.; Lutz, M.; Spek, A. L.; van Faassen, E. E.; Weckhuysen, B. M.; van Koten, G.; Klein Gebbink, R. J. M. Eur. J. Inorg. Chem. 2005 , 4, 779-788.

(18) Bruijnincx, P. C. A.; Weckhuysen, B. M.; van Koten, G.; Klein Gebbink, R. J. M. Manuscript in preparation.

(19) Weckhuysen, B. M.; Verberckmoes, A. A.; Vannijvel, I. P.; Pelgrims, J. A.; Buskens, P. L.; Jacobs, P. A.; Schoonheydt, R. A. Angew. Chem., Int. Ed. 1995, 34, 2652-2653.

(20) Weckhuysen, B. M.; Verberckmoes, A. A.; Fu, L.; Schoonheydt, R. A. J. Phys. Chem. 1996, 100, 9456-9461.

(21) Grommen, R.; Manikandan, P.; Gao, Y.; Shane, T.; Shane, J. J.; Schoonheydt, R. A.; Weckhuysen, B. M.; Goldfarb, D. J. Am. Chem. Soc. 2000, 122, 11488-11496.

(22) Baute, D.; Arieli, D.; Neese, F.; Zimmermann, H.; Weckhuysen, B. M.; Goldfarb, D. J. Am. Chem. Soc. 2004, 126, 11733-11745.

(23) Mesu, J. G.; Visser, T.; Beale, A.; Soulimani, F.; Weckhuysen, B. M. Manuscript in preparation. separation of the catalyst from the products or the selectivity of a catalytic reaction. A zeolite supercage can also be seen as a protective structure around the active center of the catalyst, similar to the protein mantle surrounding the active site of enzymes. Our group has studied in the past decade the incorporation of copper histidine (His) type complexes inside the supercages of zeolite $\mathrm{Y}$ in great detail with the aim to mimic the active site of the copper enzyme galactose oxidase. ${ }^{19-23,33,34}$ Copper histidines are intriguing biomimetic complexes, which have been widely studied in homogeneous and heterogeneous systems. However, upon immobilization, these compounds face a problem in isolating only one type of species inside the zeolite framework. Instead, there are two species present in variable amounts depending on the $\mathrm{pH}, \mathrm{Si} / \mathrm{Al}$ ratio of the zeolite support, and complex concentration in the impregnation solution. . $92,20,23,33,34^{2}$ It would be convenient to have a ligand system in which the likelihood of different coordination modes would be diminished. The novel $\mathrm{MIm}_{2} \mathrm{Pr}$ ligand is not as $\mathrm{pH}$ sensitive as histidine as there are not so many sites which could protonate/deprotonate. $\mathrm{MIm}_{2} \mathrm{Pr}$ has two substituted imidazole complexes in one ligand connected via a carbon bridge, which limits the possibilities in which the ligand could coordinate to a metal ion. It is known that $\mathrm{MIm}_{2} \mathrm{Pr}$ forms bis-ligand and dinuclear complexes in solution, and therefore, the direct impregnation or ion exchange of these complexes, as was done with copper histidines, cannot be applied. Instead, the complexes were prepared by a "shipin-a-bottle" synthesis method, ${ }^{31,36-39}$ which allows for the complex formation inside the zeolite framework, and the

(24) Seelan, S.; Sinha, A. K.; Srinivas, D.; Sivasanker, S. J. Mol. Catal. A: Chem. 2000, 157, 163-171.

(25) Chavan, S. S. D.; Ratnasamy, P. J. Catal. 2000, 192, 286-295.

(26) Bennur, T. H.; Srinivas, D.; Ratnasamy, P. Microporous Mesoporous Mater. 2001, 48, 111-118.

(27) De Vos, D. E.; Dams, M.; Sels, B. F.; Jacobs, P. A. Chem. Rev. 2002 $102,3615-3640$.

(28) Srinisivas, D.; Sivasanker, S. Catal. Surv. Asia 2003, 7, 121-132.

(29) McMorn, P.; Hutchings, G. J. Chem. Soc. Rev. 2004, 33, 108-122.

(30) Ganesan, R.; Viswanathan, B. J. Phys. Chem. B 2004, 108, 7102-7114.

(31) Caplan, N. A.; Hancock, F. E.; Bulman Page, P. C.; Hutchings, G. J. Angew. Chem., Int. Ed. 2004, 43, 1685-1688.

(32) Lee, C.-H.; Wong, S.-H.; Lin, T.-S.; Mou, C.-Y. J. Phys. Chem. B 2005, 109, 775-784.

(33) Mesu, J. G.; Baute, D.; Tromp, H. J.; van Faassen, E. E.; Weckhuysen, B. M. Stud. Surf. Sci. Catal. 2002, 143, 287-293.

(34) Mesu, J. G. Host-Guest Chemistry of $\mathrm{Cu}^{2+} /$ Histidine Complexes in Molecular Sieves. Thesis, Utrecht University, Utrecht, The Netherlands, 2005.

(35) Groothaert, M. H.; Smeets, P. J.; Sels, B. F.; Jacobs, P. A.; Schoonheydt, R. A. J. Am. Chem. Soc. 2005, 127, 1394-1395.

(36) De Vos, D. E.; Knops-Gerrits, P. P.; Parton, R. F.; Weckhuysen, B. M.; Jacobs, P. A.; Schoonheydt, R. A. J. Inclusion Phenom. Mol. Recognit. Chem. 1995, 21, 185-213.

(37) Kozlov, A.; Kozlova, A.; Asakura, K.; Iwasawa, Y. J. Mol. Catal. A: Chem. 1999, 137, 223-237.

(38) Lainé, P.; Lanz, M.; Calzaferri, G. Inorg. Chem. 1996, 35, 3514-3518. (39) Corma, A.; García, H. Top. Catal. 1998, 6, 127-140. 
resulting materials were characterized by XRF, UV/vis, ESR, and XAFS spectroscopy and tested for its oxidation activity.

\section{Experimental Section}

Materials and Synthesis Method. Zeolite $\mathrm{NaY}$ (Si/Al ratio 2.46, surface area $692 \mathrm{~m}^{2} / \mathrm{g}$, and pore volume $0.33 \mathrm{~mL} / \mathrm{g}$ ) was received from Akzo Nobel, dried in the oven at $60{ }^{\circ} \mathrm{C}$, and used as such. $\mathrm{CuCl}_{2}(98 \%), \mathrm{Cu}\left(\mathrm{NO}_{3}\right)_{2} \cdot 2.5 \mathrm{H}_{2} \mathrm{O}(98 \%)$, and $\mathrm{Cu}(\mathrm{OTf})_{2}$ $(98 \%)$ were purchased from ACROS or Aldrich and used as such. The ligand $\mathrm{MIm}_{2} \mathrm{Pr}$ was synthesized by a method described earlier by us. ${ }^{17}$ 3,5-Di-tert-butylcatechol (99\%), benzyl alcohol (99+\%), tert-butylhydroperoxide (70\% in water), and hydrogen peroxide (35\% in water) were purchased from Aldrich and used as such.

Immobilization of copper(II) complexes with the newly designed ligand $\mathrm{MIm}_{2} \mathrm{Pr}$ (Figure 1b) was achieved via the shipin-the-bottle synthesis method. ${ }^{31,36-39} \mathrm{CuCl}_{2}, \mathrm{Cu}\left(\mathrm{NO}_{3}\right)_{2}$, or $\mathrm{Cu}(\mathrm{OTf})_{2}$ was used as the copper source. For each $\mathrm{Cu}(\mathrm{II})$ source, copper ions were ion-exchanged into the zeolite $\mathrm{Y}$ with concentrations corresponding to $0.5,1,2$, or 4 copper atoms per unit cell (UC) of zeolite Y. Prior to ion exchange, the zeolite $\mathrm{NaY}$ was equilibrated to $\mathrm{pH} 7.3$ by stirring for $3 \mathrm{~h}$ in an aqueous solution with the correct $\mathrm{pH}$ and adding $\mathrm{HCl}, \mathrm{HNO}_{3}$, or $\mathrm{NaOH}$ if necessary. The copper salt was then added, and the ion exchange solution was stirred at $\mathrm{pH} 7.3$ in room temperature for $48 \mathrm{~h}$, adding $\mathrm{HCl}$ (in the case of $\mathrm{CuCl}_{2}$ ), $\mathrm{HNO}_{3}$, or $\mathrm{NaOH}$ if necessary. The ion-exchanged zeolite $\mathrm{Y}$ was then washed with water and filtered three times, dried, and the copper content was determined by XRF. The ligand $\mathrm{MIm}_{2} \mathrm{Pr}$ was introduced in the zeolite material by the incipient wetness impregnation method. The dried $\mathrm{Cu}$-zeolite $\mathrm{Y}$ material was kept under vacuum for $4-5 \mathrm{~h}$ to remove water from the pore system. The ligand was then added in either 1:1 or 1:2 ratio to the copper concentration by dissolving it in an amount of deionized water corresponding to the pore volume of the zeolite Y. For all $\mathrm{Cu}-$ zeolite $\mathrm{Y}$ samples, the ligand impregnations were done with 1:1 and 1:2 copper:ligand ratios.

Characterization Methods. UV/vis/NIR DRS measurements on solid samples were carried out on a Cary 500 diffuse reflectance spectrometer (Varian), equipped with an integrating sphere. Zeolite NaY powder was used as background. The spectra were recorded in the range of 200-2600 nm. UV/vis/ NIR measurement of the pure $\mathrm{Cu}\left(\mathrm{MIm}_{2} \mathrm{Pr}\right)_{2}$ complex was carried out on a Cary 5 diffuse reflectance spectrometer (Varian). The complex was diluted with $\mathrm{KBr}$, and pure $\mathrm{KBr}$ was used as the background. In addition, UV/vis measurements on solutions were carried out on a Cary 50 spectrometer (Varian) equipped with a probe (Hellma), which was connected to the spectrometer via optical fibers. The effective path length in the probe head was $4 \mathrm{~mm}$. The recorded range was $200-1000 \mathrm{~nm}$ with a 0.15 $\mathrm{nm}$ resolution.

ATR-IR measurements were performed on a PIKE single reflection ATR-IR unit with a resolution of $4 \mathrm{~cm}^{-1}$ in the range of $600-4000 \mathrm{~cm}^{-1}$. Ten scans were recorded per measurement. XRF measurements were carried out on a Spectro X-lab 2000 spectrometer. From the data, the amount of $\mathrm{Cu}$ atoms per unit cell of zeolite $\mathrm{Y}$ was calculated (relative to the amount of $\mathrm{Si}$ and $\mathrm{Al}$ present).

ESR measurements were performed on a Bruker ESP300E apparatus. The instrument operates near $9.5 \mathrm{GHz}$ and is equipped with a Bruker ER4103TM cavity. The samples were measured as solids or as frozen solutions at $120 \mathrm{~K}$ in a quartz tube.

$\mathrm{Cu} K$-edge XAS measurements were carried out on station BM26A at the ESRF operating at $6 \mathrm{GeV}$ in $2 / 3$ fill mode with a current of $200 \mathrm{~mA}$. The station was equipped with a $\mathrm{Si}(111)$ double crystal monochromator, and ion chambers for measuring incident and transmitted beam intensities for recording X-ray absorption spectra. A 9-element monolithic germanium detector was used for fluorescence measurements. A $10 \mu \mathrm{m} \mathrm{Cu}$ foil was used to calibrate the monochromator position. Harmonic rejection was achieved using the appropriate optics. In a typical experiment, approximately $100 \mathrm{mg}$ sample was pressed to form self-supporting wafers before being mounted in air. Measurements were performed at room temperature in normal step scanning mode over the range of $8830-9900 \mathrm{eV}$. The time taken for each scan was ca. $40 \mathrm{~min}$. To improve the signal-to-noise ratio, multiple scans were taken. XAS data were processed using the suite of programs available at Daresbury Laboratory, namely, EXCALIB (for converting the raw data to energy vs absorption coefficient), EXBROOK (for background subtraction to extract EXAFS), and EXCURV98 (to extract more detailed local structural details of the catalysts). ${ }^{40}$ An amplitude reduction factor $\left(S_{\mathrm{o}}^{2}\right)$ value of 0.9 , obtained from fitting a $\mathrm{Cu}$ metal foil, was also used in the analysis.

Multiple Scattering Calculations. Normal EXAFS data simulations are only able to yield information on the immediate near neighbor distances ( $1-2$ atomic shells) since only single scattering pathways are considered. However, it is possible to obtain a more detailed description of the local environment around the absorber (higher shell information) by performing entire EXAFS spectrum fitting and by including the effects of higher order or multiple scattering pathways. The use of 3D geometrical models has been shown to be a very powerful method to determine inter-ligand multiple scattering pathways, allowing for the detailed determination of bond distances and angles, enabling a more complete description of the local site around the absorber. ${ }^{41-43}$ Multiple scattering calculations for the $\mathrm{Cu}\left(\mathrm{MIm}_{2} \mathrm{Pr}\right)_{2}$ and $\mathrm{Cu}\left(\mathrm{MIm}_{2} \mathrm{Pr}\right) \mathrm{ZY}$ samples were performed in $C 1$ symmetry using EXCURV98. The data were fitted in $k$-space over an EXAFS range of $3.3-12.5 \AA^{-1}$ ( $k^{3}$ weighted) and $R$-range $0-5 \AA$ using $\mathrm{Rehr}-$ Albers small atom theory. ${ }^{44,45}$ To simplify the multiple scattering calculations, similar paths, which contributed less than $0.5 \%$ to the total, were ignored. To ensure that computational time was not too large, the number of atoms included in the multiple scattering path was limited to 3 and the length of the multiple scattering paths to $12 \AA$. Since the crystal structure for the $\mathrm{Cu}\left(\mathrm{MIm}_{2} \mathrm{Pr}\right)_{2}$ sample was reported earlier by $\mathrm{us}^{17}$ atomic coordinates for this structure were imported into the EXCURV98 program and only refinement of the $E_{\mathrm{f}}$ and the Debye-Waller factors was performed. To ensure that the number of refineable parameters did not exceed the number of experimental observations (free param-

(40) Binsted, N. C.; Campbell, J. W.; Gurman, S. J.; Stephenson, P. C. EXAFS Analysis Programs; Daresbury Laboratory: Warrington, 1991.

(41) Levina, A.; Armstrong, R. S.; Lay, P. A. Coord. Chem. Rev. 2005, 249 $141-160$

(42) Strange, R. W.; Ellis, M.; Hasnain, S. S. Coord. Chem. Rev. 2005, 249, 197-208.

(43) Hasnain, S. S.; Strange, R. W. J. Synchrotron Radiat. 2003, 10, 9-15.

(44) Rehr, J. J.; Albers, R. C.; Zabinsky, S. I. Phys. Rev. Lett. 1992, 69, $3397-$ 3400

(45) Rehr, J. J.; Albers, R. C. Phys. Rev. B 1990, 41, 8139-8149. 
eters), ${ }^{46}$ the Debye-Waller factors of similar types of scattering species were grouped together. A similar approach was used for $\mathrm{Cu}\left(\mathrm{MIm}_{2} \mathrm{Pr}\right) \mathrm{ZY}$ samples, although since the structure of the copper species was not known, bond distances were also allowed to vary (at first with bond distance restraints, ${ }^{47}$ although these were removed for the final refinement). The maximum number of refineable parameters used in one refinement was limited to 20 (although we calculate that over the data range used the maximum number is ca. 28). The results of the converged refinements were deemed acceptable for $R$ values of ca. $20 \%$, where only small deviations $( \pm 0.02 \AA)$ from the typical bond distances of the known crystal structure were observed. ${ }^{42,43,48}$

Catalytic Testing. Oxidation of 3,5-Di-tert-butylcatechol (DTBC): In a typical experiment, the catalyst $(6.7 \mu \mathrm{mol})$ and the substrate ( $0.34 \mathrm{mmol}, 50$ equiv) were dissolved in methanol $(15 \mathrm{~mL})$ and stirred at room temperature $(\mathrm{RT})$ under air. Product formation was monitored by UV/vis spectroscopy, as the product 3,5-di-tert-butylquinone (DTBQ) has a distinct absorption band at $400 \mathrm{~nm}\left(\epsilon=1560 \mathrm{M}^{-1} \mathrm{~cm}^{-1}\right)$. Turnover numbers (TON) were corrected for the blank reaction and calculated according to the Lambert-Beer law after $15 \mathrm{~h}$ in the case of the homogeneous complexes and after 3 days for the immobilized complexes because of the low reactivity of the latter. $\mathrm{Cu}^{2+}$ on zeolite $\mathrm{Y}(3.7 \mathrm{Cu} / \mathrm{UC})$ and bare zeolite $\mathrm{Y}$ were also tested, and they were found to have no activity under these conditions.

Oxidation of Benzyl Alcohol: In a typical experiment, the catalyst $(5.9 \mu \mathrm{mol})$ was dissolved/suspended in $1.2 \mathrm{~mL}$ of benzyl alcohol (11.8 mmol, 2000 equiv) and a known amount of mesitylene (1.2 mmol, 200 equiv, internal standard). To this solution was added $1.6 \mathrm{~mL}$ of tert-butylhydroperoxide (17.7 mmol, 3000 equiv, $70 \%$ solution in $\mathrm{H}_{2} \mathrm{O}$ ). The reaction was then stirred at constant temperature (RT or $40{ }^{\circ} \mathrm{C}$ ). After $24 \mathrm{~h}$, brine $(2 \mathrm{~mL})$ was added to the reaction mixture. In the case of the zeolite-immobilized copper catalysts, the suspended catalyst was then separated by centrifugation. The products were extracted with $\mathrm{Et}_{2} \mathrm{O}(3 \times 10 \mathrm{~mL})$, and the combined organic layers were dried over $\mathrm{MgSO}_{4}$, filtered, and concentrated in vacuo. Turnover numbers and product distribution were determined by ${ }^{1} \mathrm{H}$ NMR spectroscopy and corrected for the blank reaction.

\section{Results}

Catalyst Synthesis. A series of $\mathrm{Cu}\left(\mathrm{MIm}_{2} \mathrm{Pr}\right) \mathrm{ZY}$ samples with varying copper concentration and metal:ligand ratio were prepared and characterized. Table 1 shows the copper content (in $\mathrm{Cu}$ /unit cell) of the samples as determined by XRF before impregnation $\left(\mathrm{Cu}^{2+}\right.$ on zeolite $\left.\mathrm{Y}\right)$ and after washing of the impregnated samples, as well as the sample code for all the samples under study. It is clear that the copper content decreases dramatically upon washing in all of the samples in which the metal:ligand ratio was $1: 2$. The same trend is observed for all the samples and is independent of the initial metal content or copper precursor.

Color changes were observed after incipient wetness impregnation and washing of the samples. After impregnation, prior

(46) Koningsberger, D. C.; Mojet, B. L.; van Dorssen, G. E.; Ramaker, D. E., Top. Catal. 2000, 10, 143-155.

(47) Binsted, N.; Strange, R. W.; Hasnain, S. S. Biochemistry 1992, 31, $12117-$ 12125.

(48) Cheung, K. C.; Strange, R. W.; Hasnain, S. S. Acta Crystallogr., Sect. D: Biol. Crystallogr. 2000, 56, 697-704.
Table 1. Overview of the $\mathrm{Cu}\left(\mathrm{Mlm}_{2} \mathrm{Pr}\right) \mathrm{ZY}$ Samples Prepared with $\mathrm{CuCl}_{2}, \mathrm{Cu}\left(\mathrm{NO}_{3}\right)_{2} \cdot 2.5 \mathrm{H}_{2} \mathrm{O}$, or $\mathrm{Cu}(\mathrm{OTf})_{2}$ as the Precursor $(\mathrm{L}=$ $\mathrm{MIm}_{2} \mathrm{Pr}$ )

\begin{tabular}{|c|c|c|c|c|}
\hline sample code & $\begin{array}{c}\mathrm{Cu} \\
\text { precursor }\end{array}$ & $\begin{array}{c}{[\mathrm{Cu}]} \\
(\mathrm{Cu} / \mathrm{UC})\end{array}$ & $\begin{array}{l}\text { Cu:L } \\
\text { ratio }\end{array}$ & $\begin{array}{l}\text { [Cu] after washing } \\
\text { (Cu/UC) }\end{array}$ \\
\hline $\mathrm{Cu}\left(\mathrm{MIm}_{2} \mathrm{Pr}\right) \mathrm{ZY} 1$ & $\mathrm{CuCl}_{2}$ & 0.9 & $1: 1$ & 0.5 \\
\hline $\mathrm{Cu}\left(\mathrm{MIm}_{2} \mathrm{Pr}\right) \mathrm{ZY} 2$ & & & $1: 2$ & 0.2 \\
\hline $\mathrm{Cu}\left(\mathrm{MIm}_{2} \mathrm{Pr}\right) \mathrm{ZY} 3$ & & 1.8 & $1: 1$ & 1.8 \\
\hline $\mathrm{Cu}\left(\mathrm{MIm}_{2} \mathrm{Pr}\right) \mathrm{ZY} 4$ & & & $1: 2$ & 0.3 \\
\hline $\mathrm{Cu}\left(\mathrm{MIm}_{2} \mathrm{Pr}\right) \mathrm{ZY} 5$ & & 3.7 & $1: 1$ & 3.0 \\
\hline $\mathrm{Cu}\left(\mathrm{MIm}_{2} \mathrm{Pr}\right) \mathrm{ZY} 6$ & & & $1: 2$ & 0.1 \\
\hline $\mathrm{Cu}\left(\mathrm{MIm}_{2} \mathrm{Pr}\right) \mathrm{ZY} 7$ & $\mathrm{Cu}\left(\mathrm{NO}_{3}\right)_{2}$ & 0.9 & $1: 1$ & 0.8 \\
\hline $\mathrm{Cu}\left(\mathrm{MIm}_{2} \mathrm{Pr}\right) \mathrm{ZY} 8$ & & & $1: 2$ & 0.3 \\
\hline $\mathrm{Cu}\left(\mathrm{MIm}_{2} \mathrm{Pr}\right) \mathrm{ZY} 9$ & & 1.6 & $1: 1$ & 1.6 \\
\hline $\mathrm{Cu}\left(\mathrm{MIm}_{2} \mathrm{Pr}\right) \mathrm{ZY} 10$ & & & $1: 2$ & 0.3 \\
\hline $\mathrm{Cu}\left(\mathrm{MIm}_{2} \mathrm{Pr}\right) \mathrm{ZY} 11$ & & 3.9 & $1: 1$ & 1.6 \\
\hline $\mathrm{Cu}\left(\mathrm{MIm}_{2} \mathrm{Pr}\right) \mathrm{ZY} 12$ & & & $1: 2$ & 0.2 \\
\hline $\mathrm{Cu}\left(\mathrm{MIm}_{2} \mathrm{Pr}\right) \mathrm{ZY} 13$ & $\mathrm{Cu}(\mathrm{OTf})_{2}$ & 1.0 & $1: 1$ & 0.9 \\
\hline $\mathrm{Cu}\left(\mathrm{MIm}_{2} \mathrm{Pr}\right) \mathrm{ZY} 14$ & & & $1: 2$ & 0.2 \\
\hline $\mathrm{Cu}\left(\mathrm{MIm}_{2} \mathrm{Pr}\right) \mathrm{ZY} 15$ & & 1.9 & $1: 1$ & 1.2 \\
\hline $\mathrm{Cu}\left(\mathrm{MIm}_{2} \mathrm{Pr}\right) \mathrm{ZY} 16$ & & & $1: 2$ & 0.3 \\
\hline
\end{tabular}

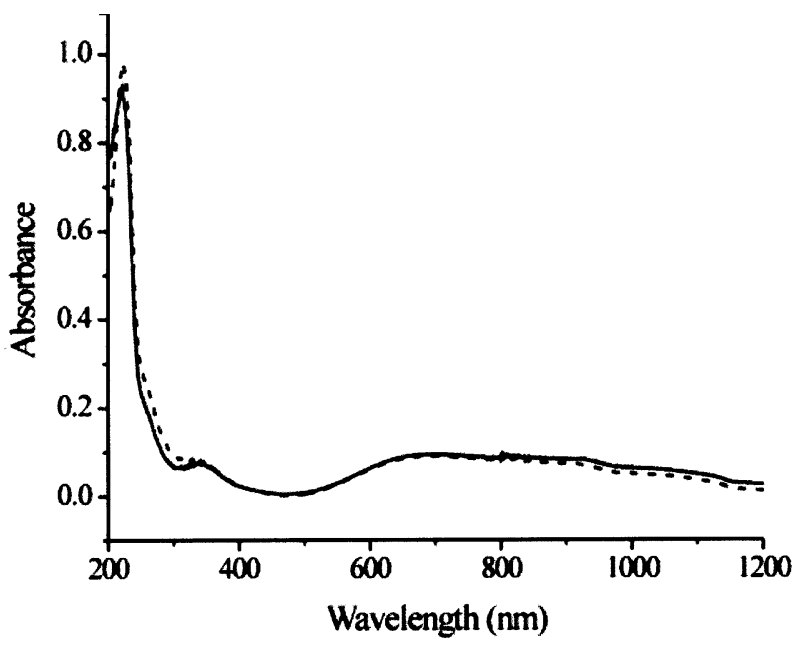

Figure 2. $\mathrm{DRS}$ spectra of $\mathrm{Cu}\left(\mathrm{MIm}_{2} \mathrm{Pr}\right) \mathrm{ZY} 3$ sample with a $1: 1 \mathrm{Cu}$ :ligand ratio before (- - ) and after (-) washing.

to washing, the $1: 1$ samples were pale blue, whereas the $1: 2$ samples were purple. After washing, the 1:1 samples remain pale blue (colorless filtrate), whereas the 1:2 samples become as pale blue as the 1:1 samples, losing the purple color in the filtrate. This behavior is observed for all the samples. Therefore, it is apparent that different species are formed upon impregnation depending on the $\mathrm{Cu}$ :ligand ratio, but not on the metal content or the counteranion in the copper salt. The nature of these different species has been studied in great detail making use of UV/vis, ATR-IR, ESR, and XAFS spectroscopies.

UV/Vis/NIR DRS. The UV/vis/NIR DRS spectra of all $\mathrm{Cu}\left(\mathrm{MIm}_{2} \mathrm{Pr}\right) \mathrm{ZY}$ samples show at least three absorption bands (two in the UV part and one in the visible part of the spectrum), whereas in some of the spectra, an additional shoulder is present in the UV (see Figures 2 and 3 and the results shown in Table 2 ). The coordination of an imidazole group to $\mathrm{Cu}^{2+}$ is known to give rise to a characteristic band pattern in the UV part of the absorption spectrum. ${ }^{49-53}$ This type of absorption originates

(49) Bernarducci, E.; Schwindinger, W. F.; Hughey, J. L.; Krogh-Jespersen, K.; Schugar, H. J. J. Am. Chem. Soc. 1981, 103, 1686-1691.

(50) Fawcett, T. G.; Bernarducci, E. E.; Krogh-Jespersen, K.; Schugar, H. J., J. Am. Chem. Soc. 1980, 102, 2598-2604.

(51) Wilson, E. W.; Kasperian, M. H.; Martin, R. B. J. Am. Chem. Soc. 1970, 92, 5364-5372. 


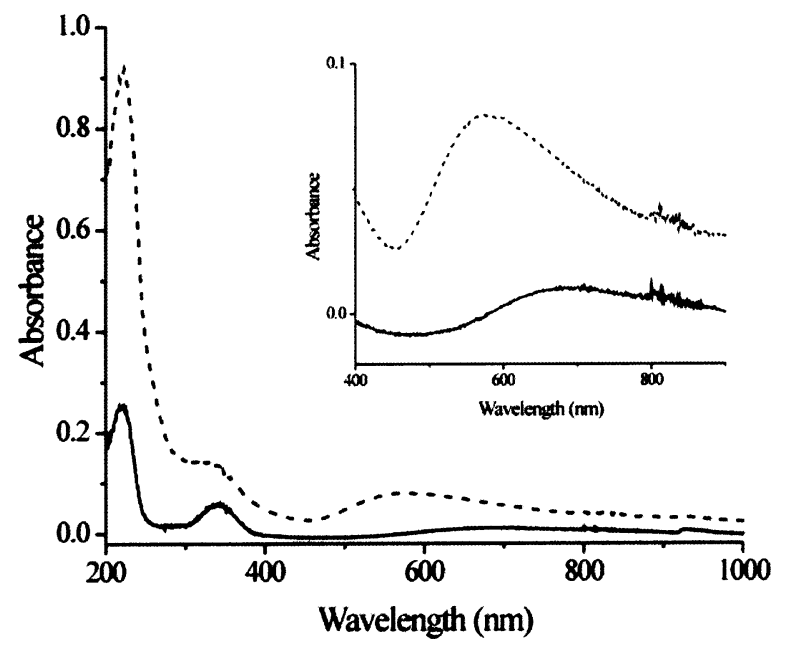

Figure 3. DRS spectra of $\mathrm{Cu}\left(\mathrm{MIm}_{2} \mathrm{Pr}\right) \mathrm{ZY} 4$ sample with a 1:2 $\mathrm{Cu}$ :ligand ratio before (- - -) and after (-) washing. The inset shows the $\mathrm{d}-\mathrm{d}$ transition region.

Table 2. The UV/Vis Absorption Bands of the Zeolite-Immobilized $\mathrm{Cu}\left(\mathrm{Mlm}_{2} \mathrm{Pr}\right)$ Complexes Together with Some Relevant Reference Compounds (sh $=$ shoulder $)$

\begin{tabular}{ll}
\hline \multicolumn{1}{c}{ compound } & \multicolumn{1}{c}{$\lambda_{\max }$ UV/vis absorption } \\
bands $(\mathrm{nm})$
\end{tabular}

from ligand-to-metal charge transfer (LMCT) transitions of the higher lying orbitals of the imidazole ring to the $\mathrm{Cu}^{2+}$ cation. Next to a $\sigma$-lone pair there are two filled $\pi$-type orbitals on the imidazole ring that are high in energy, ${ }^{50}$ and as a consequence, three LMCT transitions from these orbitals to the empty $\sigma^{*}\left(x^{2}-y^{2}\right)$ orbital on the $\mathrm{Cu}^{2+}$ cation can occur. The transition from the lone pair is highest in energy (at around $220 \mathrm{~nm}$ ), and its intensity is independent of the orientation of the imidazole ring with respect to the $\mathrm{Cu}^{2+}$ cation. The other two LMCT transitions are lower in energy, ${ }^{50}$ and the position and intensity of the corresponding bands is less well-defined, as they depend on the orientation of the imidazole ring to the $\mathrm{Cu}^{2+}$ cation. ${ }^{53}$

The LMCT bands at 221 and $340 \mathrm{~nm}$ are present in all the samples, whereas the shoulder at $270 \mathrm{~nm}$ is only present in the samples that were impregnated with a $1: 1 \mathrm{Cu}$ :ligand ratio. The $\lambda_{\max }$ of the $\mathrm{d}-\mathrm{d}$ transition band changes depending on the metalto-ligand ratio in the unwashed samples. The samples prepared with a metal-to-ligand ratio of 1:1 exhibit a $d-d$ transition with a $\lambda_{\max }$ at $690 \mathrm{~nm}$, whereas the samples prepared with a metalto-ligand ratio of 1:2 show their $\lambda_{\max }$ at about $590 \mathrm{~nm}$. Upon washing, the spectra of the 1:1 complexes do not change (Figure 2). However, significant changes are observed in the spectra of the 1:2 complexes. In these spectra, the intensity of the band at $221 \mathrm{~nm}$ decreases significantly, and the position of the $\mathrm{d}-\mathrm{d}$ transition shifts to $690 \mathrm{~nm}$ after washing (Figure 3). As noted from Table 1, the copper content of the 1:2 samples decreases

(52) Bernarducci, E.; Bharadwaj, P. K.; Krogh-Jespersen, K.; Potenza, J. A.; Schugar, H. J. J. Am. Chem. Soc. 1983, 105, 3860-3866.

(53) Lever, A. B. P. Inorganic Electronic Spectroscopy; Elsevier Science BV: Amsterdam, 1984

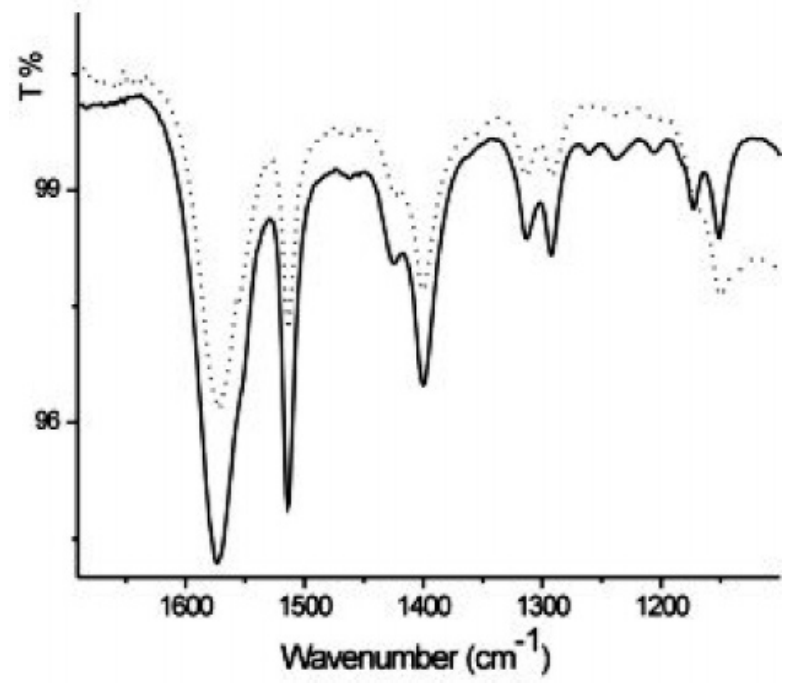

Figure 4. The ATR-IR spectra of the $\mathrm{Cu}\left(\mathrm{MIm}{ }_{2} \mathrm{Pr}\right)_{2}$ complex in water $(-)$ and of the washing filtrate of $\mathrm{Cu}\left(\mathrm{MIm}_{2} \mathrm{Pr}\right) \mathrm{ZY} 13$ sample with 1:2 copper:ligand ratio $(\cdots)$

upon washing. Thus, the decrease in the copper content and in the intensity of the absorption at $221 \mathrm{~nm}$ suggests that part of the complex formed during the impregnation of the 1:2 samples is removed during the washing step.

The energy shift and intensity decrease for the $\mathrm{Cu}\left(\mathrm{MIm}_{2} \mathrm{Pr}\right)$ ZY 1:2 complexes after washing suggest that the species with a d $-\mathrm{d}$ transition $\lambda_{\max }$ at around $590 \mathrm{~nm}$ is removed by washing. Indeed, when a UV/vis spectrum of the washing filtrate of these compounds (after evaporation and dissolution in $\mathrm{MeOH}$ ) is measured, $\lambda_{\max }$ of the $\mathrm{d}-\mathrm{d}$ transition is observed at $587 \mathrm{~nm}$. Comparison of the spectra of the immobilized $\mathrm{Cu}\left(\mathrm{MIm}{ }_{2} \mathrm{Pr}\right) \mathrm{ZY}$ samples and their washing filtrate with the spectra of $\mathrm{Cu}\left(\mathrm{MIm}{ }_{2} \mathrm{Pr}\right)_{2}$ complexes in the solid state and in solution indicates that it is the $\mathrm{Cu}\left(\mathrm{MIm}_{2} \mathrm{Pr}\right)_{2}$ complex that is washed out of the zeolite during the washing step of the 1:2 samples. This is clear from the overview of the UV/vis spectra presented in Table 2.

ATR/IR Spectroscopy. The similarity between the compound in the washing filtrate and the homogeneous $\mathrm{Cu}\left(\mathrm{MIm}{ }_{2} \mathrm{Pr}\right)_{2}$ complex was confirmed by the ATR-IR spectra of the two solutions, which are shown in Figure 4. The two spectra are identical, indicating that the complexes in the two solutions are the same.

ESR Spectroscopy. ESR is a proven technique to locate copper(II) ion sites and to give information about the site symmetry around the $\mathrm{Cu}$ (II) ions. ${ }^{20,32,54,55}$ The ESR spectra confirm the observations made with UV/vis/NIR spectroscopy. Two species can be observed in the unwashed 1:2 samples (further referred to as $\mathbf{1}$ and 2, Figure 5), whereas only species $\mathbf{1}$ is present in the washed 1:2 samples and in all 1:1 samples. Species $\mathbf{1}$ is characterized by a five-line superhyperfine splitting $\left(A_{\perp, \mathrm{N}}\right.$ of about $14.5 \mathrm{G}$, indicated in the inset in Figure 5 ), which is indicative for the presence of two nitrogen atoms surrounding the copper center. The lower value for $g_{\|}$and the higher value for $A_{\|}$of species $\mathbf{2}$ with respect to species $\mathbf{1}$ indicate the presence of more nitrogen atoms coordinating to the copper in species 2 with respect to species $\mathbf{1}$. Uncomplexed $\mathrm{Cu}^{2+}$ on zeolite $\mathrm{Y}\left(g_{\|}\right.$

(54) Turnes Palomino, G.; Fisicaro, P.; Bordiga, S.; Zecchina, A.; Giamello, E.; Lamberti, C. J. Phys. Chem. B 2000, 104, 4064-4073.

(55) Delabie, A.; Pierloot, K.; Groothaert, M. H.; Schoonheydt, R. A.; Vanquickenborne, L. G. Eur. J. Inorg. Chem. 2002, 515-530. 


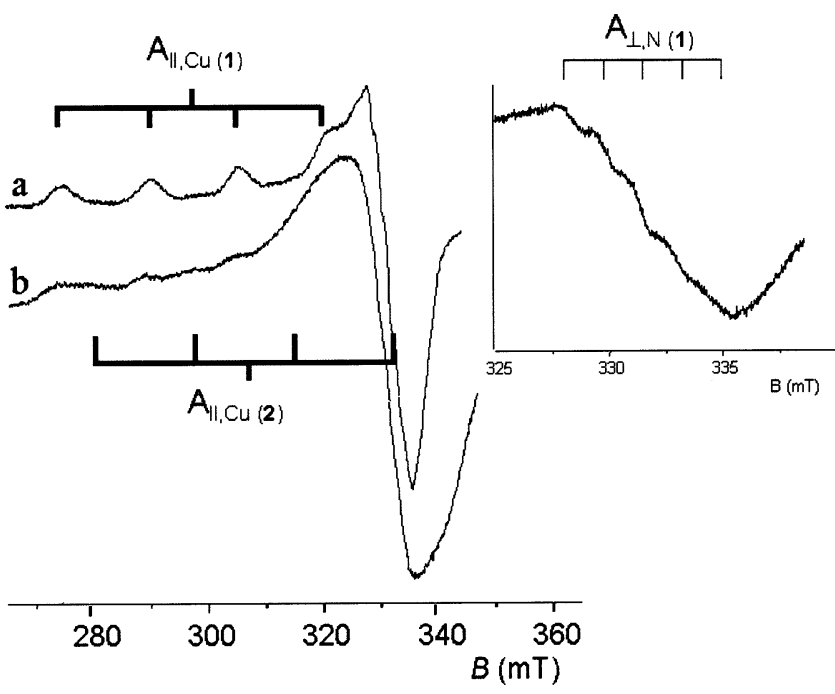

Figure 5. ESR spectra of the washed (a) and unwashed (b) $\mathrm{Cu}\left(\mathrm{MIm}_{2} \mathrm{Pr}\right) \mathrm{ZY}$ initially with a Cu:ligand ratio of 1:2. The inset shows the region of the superhyperfine splitting in top spectrum.

Table 3. Overview of ESR and UV-Vis Parameters for Some of the Immobilized Zeolite Samples and, for Comparison, a Number of Reference Compounds Possessing Similar N/O Coordination

\begin{tabular}{|c|c|c|c|c|c|}
\hline compound & $g_{\|}$ & $A_{\|}(\mathrm{G})$ & $A_{\perp}(\mathrm{G})$ & $\begin{array}{c}\mathrm{d}-\mathrm{d} \text { transition } \\
\left(\mathrm{cm}^{-1}\right)\end{array}$ & $\begin{array}{l}\text { coordination } \\
\text { around copper }\end{array}$ \\
\hline $\mathrm{Cu}(\mathrm{M}$ & 2.31 & 160 & 14.5 & $14500(690 \mathrm{~nm})$ & $\mathrm{NNO} \mathrm{OO}^{a}$ \\
\hline $\mathrm{Cu}\left(\mathrm{MIm}_{2} \mathrm{Pr}\right) \mathrm{ZY} 2$ & 2.22 & 195 & & $17040(587 \mathrm{~nm})^{b}$ & NNNN OO \\
\hline $\mathrm{Cu}\left(\mathrm{MIm}_{2} \mathrm{Pr}\right)_{2}$ solid $^{17}$ & 2.22 & 200 & 15.5 & $17040(587 \mathrm{~nm})$ & NNNN OO \\
\hline $\mathrm{Cu}\left(\mathrm{MIm}_{2} \mathrm{Pr}\right)_{2}$ solution ${ }^{17}$ & 2.24 & 193 & & $17040(587 \mathrm{~nm})^{b}$ & $\mathrm{NOO}$ \\
\hline $\mathrm{Cu}$ (his) complex $\mathrm{A}^{20,33,34}$ & 2.31 & 158 & & $14500(690 \mathrm{~nm})^{c}$ & NNOO O \\
\hline $\mathrm{Cu}(\mathrm{his})$ complex $\mathrm{B}^{20,33,34}$ & 2.25 & 183 & 13 & $16100(621 \mathrm{~nm})^{d}$ & NNNO OO \\
\hline
\end{tabular}

${ }^{a}$ Proposed coordination. ${ }^{b}$ In methanol. ${ }^{c}$ Sample with $80 \%$ complex A. ${ }^{d}$ Sample with $70 \%$ complex B.

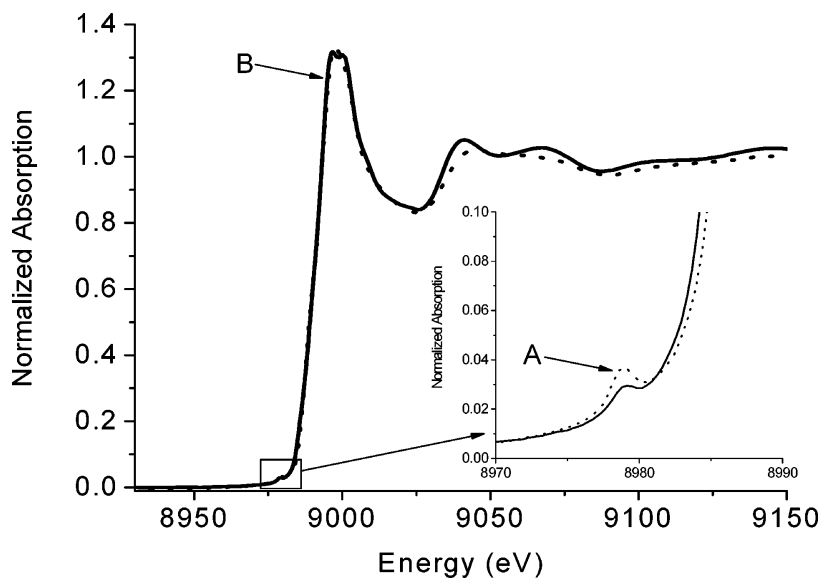

Figure 6. Comparative XANES spectra of $\mathrm{Cu}\left(\mathrm{MIm}_{2} \mathrm{Pr}\right)_{2}$ (solid line) and $\mathrm{Cu}\left(\mathrm{MIm}_{2} \mathrm{Pr}\right) \mathrm{ZY} 1$ (dashed line) with inset highlighting the differences in the intensity of the $1 \mathrm{~s}-3 \mathrm{~d}$ transition (feature A) at $8979 \mathrm{eV}$. The $1 \mathrm{~s}-4 \mathrm{p}$ transition is also marked (feature B).

$=2.39$ and $A_{\|}=129 \mathrm{G}$ ) is not observed in any of the samples. In line with the UV/vis results, also the ESR parameters are the same for all washed complexes, independent of copper concentration or the precursor used for the ion exchange. The $A_{\|}$and $g_{\|}$values of species $\mathbf{1}$ and $\mathbf{2}$ are summarized in Table 3, together with some relevant reference compounds.

XAFS Spectroscopy: XANES Analysis. Figure 6 shows the normalized X-ray absorption edge data for solid $\mathrm{Cu}\left(\mathrm{MIm}_{2} \mathrm{Pr}\right)_{2}$ and the $\mathrm{Cu}\left(\mathrm{MIm}_{2} \mathrm{Pr}\right) \mathrm{ZY} 1$ sample. Both spectra are very similar.
Table 4. Parameters Derived from EXAFS Fit for the $\mathrm{Cu}\left(\mathrm{Mlm}_{2} \mathrm{Pr}\right)_{2}$ Complex: Details of the Significant Multiple Scattering Pathways Determined from the Analysis of the EXAFS are Given in Table A of the Supporting Information

\begin{tabular}{llll}
\hline \multicolumn{1}{c}{ shells } & $N$ & $R(\AA)$ & $2 \sigma^{2}\left(\AA^{2}\right)$ \\
\hline $\mathrm{Cu}-\mathrm{N}_{(1-4)}$ & 4 & 1.99 & $0.006^{a}$ \\
$\mathrm{Cu}-\mathrm{O}(5,6)$ & 2 & 2.36 & 0.037 \\
$\mathrm{Cu}-\mathrm{C}_{(7,8)}$ & 2 & 2.94 & 0.005 \\
$\mathrm{Cu}-\mathrm{C}_{(9,10)}$ & 2 & 2.95 & 0.005 \\
$\mathrm{Cu}-\mathrm{C}_{(11,12)}$ & 2 & 3.06 & 0.005 \\
$\mathrm{Cu}-\mathrm{C}_{(13,14)}$ & 2 & 3.09 & 0.005 \\
$\mathrm{Cu}-\mathrm{C}_{(15,16)}$ & 2 & 3.34 & 0.026 \\
$\mathrm{Cu}-\mathrm{C}_{(17,18)}$ & 2 & 3.35 & 0.026 \\
$\mathrm{Cu}-\mathrm{C}_{(19,20)}$ & 2 & 3.88 & 0.026 \\
$\mathrm{Cu}-\mathrm{N}_{(21,22)}$ & 2 & 4.11 & 0.015 \\
$\mathrm{Cu}-\mathrm{N}_{(23,24)}$ & 2 & 4.13 & 0.015 \\
$\mathrm{Cu}-\mathrm{C}_{(25,26)}$ & 2 & 4.17 & 0.015 \\
$\mathrm{Cu}-\mathrm{C}_{(27,28)}$ & 2 & 4.21 & 0.015 \\
$\mathrm{Cu}-\mathrm{O}_{(29,30)}$ & 2 & 4.36 & 0.026 \\
\hline
\end{tabular}

${ }^{a} E_{\mathrm{f}}=-1.06 \mathrm{eV}, R=17.96 \%$.

The edge position at $8990 \mathrm{eV}$ and the position of a pre-edge peak at $8979 \mathrm{eV}$ in both samples are consistent with the presence of $\mathrm{Cu}$ (II) species. ${ }^{56,57}$

However, the intensity of the pre-edge peak (labeled feature A) for $\mathrm{Cu}\left(\mathrm{MIm}_{2} \mathrm{Pr}\right) \mathrm{ZY} 1$ is almost twice that of $\mathrm{Cu}\left(\mathrm{MIm}_{2} \mathrm{Pr}\right)_{2}$. This feature has previously been assigned to a $1 \mathrm{~s}-3 \mathrm{~d}$ quadrupole or dipole transition, which is known to be sensitive to the coordination environment around the absorber. ${ }^{58-60}$ It has been shown that both the symmetry of the environment and atomic orbital mixing $(3 d-4 p$ mixing) can affect both its shape and intensity. In coordination states where the number of near neighbors is $<6$, shorter metal-oxygen bond distances result in greater $\mathrm{d}-\mathrm{p}$ overlap and more $\mathrm{p}$ character to the transition making it more "dipole allowed" and therefore more intense. ${ }^{58,61}$ In such circumstances, feature B $(1 s-4 p$ dipole transition) becomes more "dipole forbidden" and decreases in intensity. However, in this case, no reduction in $1 s-4 p$ intensity was observed for $\mathrm{Cu}\left(\mathrm{MIm}_{2} \mathrm{Pr}\right) \mathrm{ZY} 1$, suggesting that a change of symmetry from the centrosymmetric distorted octahedra in the $\mathrm{Cu}\left(\mathrm{MIm}_{2} \mathrm{Pr}\right)_{2}$ to that of a noncentrosymmetric environment is the most likely cause of the increase in feature A. However, to further verify this observation, detailed analysis of the EXAFS data needed to be undertaken.

EXAFS Analysis: EXAFS analysis was performed first using single scattering analysis to determine the immediate local structure around the copper in the $\mathrm{Cu}\left(\mathrm{MIm}_{2} \mathrm{Pr}\right) \mathrm{ZY} 1$ sample, followed by an entire EXAFS spectra fit using multiple scattering analysis to obtain a more detailed description. For comparison and for determining a suitable starting point in the refinement, data from the known crystal structure of $\mathrm{Cu}\left(\mathrm{MIm}_{2} \mathrm{Pr}\right)_{2}$ were fitted first. The results from the analysis are given in Table 4.

A fit of the first shell data for $\mathrm{Cu}\left(\mathrm{MIm}_{2} \mathrm{Pr}\right)_{2}$ yielded two shells corresponding to 4 equatorial $\mathrm{N}$ at $1.99 \AA$ and 2 axial oxygens at $2.36 \AA$, which compare well with the average crystallographic

(56) Strange, R. W.; Reinhammar, B.; Murphy, L. M.; Hasnain, S. S. Biochemistry 1995, 34, 220-231.

(57) Shimizu, K.; Maeshima, H.; Yoshida, H.; Satsuma, A.; Hattori, T. Phys. Chem. Chem. Phys. 2001, 3, 862-866.

(58) Westre, T. E.; Kennepohl, P.; DeWitt, J. G.; Hedman, B.; Hodgson, K. O.; Solomon, E. I. J. Am. Chem. Soc. 1997, 119, 6297-6314.

(59) Wilke, M.; Farges, F.; Petit, P. E.; Brown, G. E.; Martin, F. Am. Mineral. 2001, 86, 714-730.

(60) Sano, M.; Komorita, S.; Yamatera, H. Inorg. Chem. 1992, 31, 459-463. (61) Bart, J. C. J. Adv. Catal. 1986, 34, 203-296. 
Table 5. Parameters Derived from EXAFS Fit for $\mathrm{Cu}\left(\mathrm{MIm} \mathrm{m}_{2} \mathrm{Pr}\right) \mathrm{ZY} 1$ Using Both Single Scattering and Multiple Scattering Calculations: Details of the Significant Multiple Scattering Pathways Determined from the Analysis of the EXAFS are Given in Table B of the Supporting Information

\begin{tabular}{llll}
\hline \multicolumn{1}{c}{ shells } & $N$ & $R(\AA)$ & $2 \sigma^{2}\left(\AA^{2}\right)$ \\
\hline $\mathrm{Cu}-\mathrm{N} / \mathrm{O}$ & 4 & 1.97 & $0.009^{a}$ \\
$\mathrm{Cu}-\mathrm{O}($ axial $)$ & 0.9 & 2.36 & 0.037 \\
$\mathrm{Cu}-\mathrm{O}_{1}$ & 1 & 1.96 & $0.009^{b}$ \\
$\mathrm{Cu}-\mathrm{N}_{2}$ & 1 & 1.94 & 0.009 \\
$\mathrm{Cu}-\mathrm{O}_{3}$ & 1 & 1.97 & 0.009 \\
$\mathrm{Cu}-\mathrm{N}_{4}$ & 1 & 2.01 & 0.009 \\
$\mathrm{Cu}-\mathrm{O}_{5}$ & 1 & 2.37 & 0.037 \\
$\mathrm{Cu}-\mathrm{C}_{7}$ & 1 & 2.89 & 0.005 \\
$\mathrm{Cu}-\mathrm{C}_{8}$ & 1 & 2.93 & 0.005 \\
$\mathrm{Cu}-\mathrm{C}_{9}$ & 1 & 3.01 & 0.005 \\
$\mathrm{Cu}-\mathrm{C}_{10}$ & 1 & 3.10 & 0.005 \\
$\mathrm{Cu}-\mathrm{C}_{11}$ & 1 & 3.30 & 0.026 \\
$\mathrm{Cu}-\mathrm{C}_{12}$ & 1 & 3.34 & 0.026 \\
$\mathrm{Cu}-\mathrm{C}_{13}$ & 1 & 3.85 & 0.026 \\
$\mathrm{Cu}-\mathrm{N}_{14}$ & 1 & 4.06 & 0.015 \\
$\mathrm{Cu}-\mathrm{N}_{15}$ & 1 & 4.12 & 0.015 \\
$\mathrm{Cu}-\mathrm{C}_{16}$ & 1 & 4.12 & 0.015 \\
$\mathrm{Cu}-\mathrm{C}_{17}$ & 1 & 4.21 & 0.015 \\
$\mathrm{Cu}-\mathrm{O}_{18}$ & 1 & 4.36 & 0.026 \\
\hline
\end{tabular}

${ }^{a} E_{\mathrm{f}}=-1.78 \mathrm{eV}, R=26.45 \% .{ }^{b} E_{\mathrm{f}}=-1.27 \mathrm{eV}, R=22.93 \%$.

distances of $4 \mathrm{~N}$ at $2.00 \AA$ and 2 oxygens at $2.40 \AA$ obtained from the single-crystal data. ${ }^{17}$ However, as can be seen from Table 4, the Debye-Waller factors for the axial oxygens are abnormally high $\left(0.037 \AA^{2}\right)$. The origin of this problem is described in the Supporting Information (Figure c).

Detailed analysis of the first shell for the $\mathrm{Cu}\left(\mathrm{MIm}_{2} \mathrm{Pr}\right) \mathrm{ZY} 1$ sample was also complicated by this problem (see Table 5). Therefore, to determine further whether the $\mathrm{Cu}(\mathrm{II})$ species remained as a distorted octahedral-like structure, refinement of the coordination numbers (and $E_{\mathrm{f}}$ and bond distances) was performed with fixed Debye-Waller factors. The values obtained for the two coordination shells (shell 1, $N=3.9$ (1.97 $\AA)$, and shell $2, N=0.9(2.36 \AA)$ ) do suggest that the coordination of copper in the $\mathrm{Cu}\left(\mathrm{MIm}_{2} \mathrm{Pr}\right) \mathrm{ZY} 1$ sample tends toward a distorted 5-fold coordination, which is therefore very similar to the copper environment observed previously for the $\mathrm{Cu}^{2+}$ aqua ion. ${ }^{62,63}$ However, it is not possible to rule out the presence of an additional axial ligand at distances longer than $2.4 \AA$.

Considering the results obtained from the ESR data (which showed that a Cu:ligand ratio of 1 was present in the zeolite) and a comparison of the Fourier transform intensity between the $\mathrm{Cu}\left(\mathrm{MIm}_{2} \mathrm{Pr}\right)_{2}$ and $\mathrm{Cu}\left(\mathrm{MIm}_{2} \mathrm{Pr}\right) \mathrm{ZY} 1$ samples, for the full profile fitting of $\mathrm{Cu}\left(\mathrm{MIm}_{2} \mathrm{Pr}\right) \mathrm{ZY} 1$, a starting point for the refinement was the $\mathrm{Cu}\left(\mathrm{MIm}_{2} \mathrm{Pr}\right)_{2}$ complex with one of the ligands removed and the $2 \mathrm{~N}$ atoms from this missing ligand replaced with $2 \mathrm{O}$ (determined to be from zeolite or from water).

It was clear that this simple approach already yielded a good fit of the data, suggesting that the starting point is close to the final solution. However, since it is likely that some distortion of the structure may occur as a result of incorporation into the zeolite, a refinement of the data was performed, and the results of the fit are shown in Figure 7 and the final structure is given in Figure 8.

(62) Pasquarello, A.; Petri, I.; Salmon, P. S.; Parisel, O.; Car, R.; Toth, E.; Powell, D. H.; Fischer, H. E.; Helm, L.; Merbach, A. E. Science 2001, 291, 856859 .

(63) Benfatto, M.; D’Angelo, P.; Della Longa, S.; Pavel, N. V. Phys. Rev. B 2002, 65, 174205-1-174205-5.
The analysis yielded again a reasonably good fit of the data $(R=22.93)$ with very similar Debye-Waller factors and distances for the higher shells as seen for the $\mathrm{Cu}\left(\mathrm{MIm}_{2} \mathrm{Pr}\right)_{2}$ complex. This would suggest that zeolite incorporation did not cause too much distortion of the complex but that a rather unique copper environment had been stabilized in which $\mathrm{Cu}(\mathrm{II})$ was now coordinated to one ligand (still tridentate in nature) and two oxygens. Such a copper site is noncentrosymmetric, which is consistent with the increased $1 \mathrm{~s}-3 \mathrm{~d}$ transition intensity seen in the XANES data. ${ }^{57}$ However, as highlighted in Figure 7 by the downward pointing arrows, there is a certain degree of mismatch in the simulation and the experimental FTs which is most likely to be caused by scattering from the zeolite framework (since it was not clear whether one or a greater number of oxygen ligands are coordinated to the zeolite framework, it was not possible to determine an appropriate site for the complex so that it would be possible to determine the zeolite contribution in the EXAFS). Most interestingly, the derived distances from the first shell analysis are consistent with other similar $\mathrm{Cu}$ (II)-containing structures in which $\mathrm{Cu}$ (II) adopts a distorted square-based pyramid geometry. ${ }^{63}$

Catalytic Experiments. To determine if the immobilized copper species were still accessible and catalytically active, we tried the immobilized complexes as catalysts in the oxidation of 3,5-di-tert-butylcatechol (DTBC) and benzyl alcohol using air and tert-butylhydroperoxide, respectively, as the terminal oxidant. The aerial oxidation of ortho-diphenols (catechols) to ortho-quinones requires the presence of two copper ions in close proximity. ${ }^{64-66}$ The benchmark substrate DTBC is relatively easily oxidized by copper complexes in which two copper centers can facilitate binding of the substrate and is therefore often used to test for this catechol oxidase activity of synthetic copper(II) complexes. The product 3,5-di-tert-butylquinone (DTBQ) has a distinct absorption at $400 \mathrm{~nm}$, and the reaction can thus be easily monitored by UV-vis spectroscopy. Since dinuclear complexes can be isolated from the homogeneous phase, such as $\left[\mathrm{Cu}_{2}\left(\mathrm{MIm}_{2} \mathrm{Pr}\right)_{2}(\mathrm{OTf})_{2}\right],{ }^{18}$ they are in principle possible coordination modes for the immobilized complexes and therefore were also tested for this reactivity. The formation and retention of these dinuclear, neutral species within the zeolite framework is, however, unlikely due to spatial constraints and lack of interaction with the framework. Indeed, whereas the dinuclear complex $\left[\mathrm{Cu}_{2}\left(\mathrm{MIm}_{2} \mathrm{Pr}\right)_{2}(\mathrm{OTf})_{2}\right]$ catalyzes the oxidation of DTBC with a fair initial rate and a TON of 6.2 after $15 \mathrm{~h}$, the tested compounds $\mathrm{Cu}\left(\mathrm{MIm}_{2} \mathrm{Pr}\right) \mathrm{ZY} 1$ and $\mathrm{Cu}\left(\mathrm{MIm}_{2} \mathrm{Pr}\right) \mathrm{ZY} 5$, however, showed negligible activity in this reaction $(2.7 \mathrm{TON}$ after three full days for $\mathrm{Cu}\left(\mathrm{MIm}_{2} \mathrm{Pr}\right) \mathrm{ZY} 1$ and $\mathrm{TON}<1$ for $\left.\mathrm{Cu}\left(\mathrm{MIm}_{2} \mathrm{Pr}\right) \mathrm{ZY} 5\right)$. These results are in agreement with the spectroscopic data presented above and indicate that dinuclear complexes are not present in the zeolite and that there are no two copper centers in close proximity to catalyze this reaction.

The lack of activity in the oxidation of DTBC leaves us with the question whether the immobilized copper species is still accessible and catalytically active. Since the structurally related copper(II)-histidine complexes immobilized on zeolite $\mathrm{Y}$ $\left.\left([\mathrm{Cu} \text { (histidine })_{2}\right] \mathrm{ZY}\right)$ are known to be active catalysts in the

(64) Merkel, M.; Möller, N.; Piacenza, M.; Grimme, S.; Rompel, A.; Krebs, B. Chem.-Eur. J. 2005, 11, 1201-1209.

(65) Ackermann, J.; Meyer, F.; Kaifer, E.; Pritzkow, H. Chem.-Eur. J. 2002, $8,247-258$.

(66) Thirumavalavan, M.; Akilan, P.; Kandaswamy, M.; Chinnakali, K.; Kurnar, G. S.; Fun, H. K. Inorg. Chem. 2003, 42, 3308-3317. 

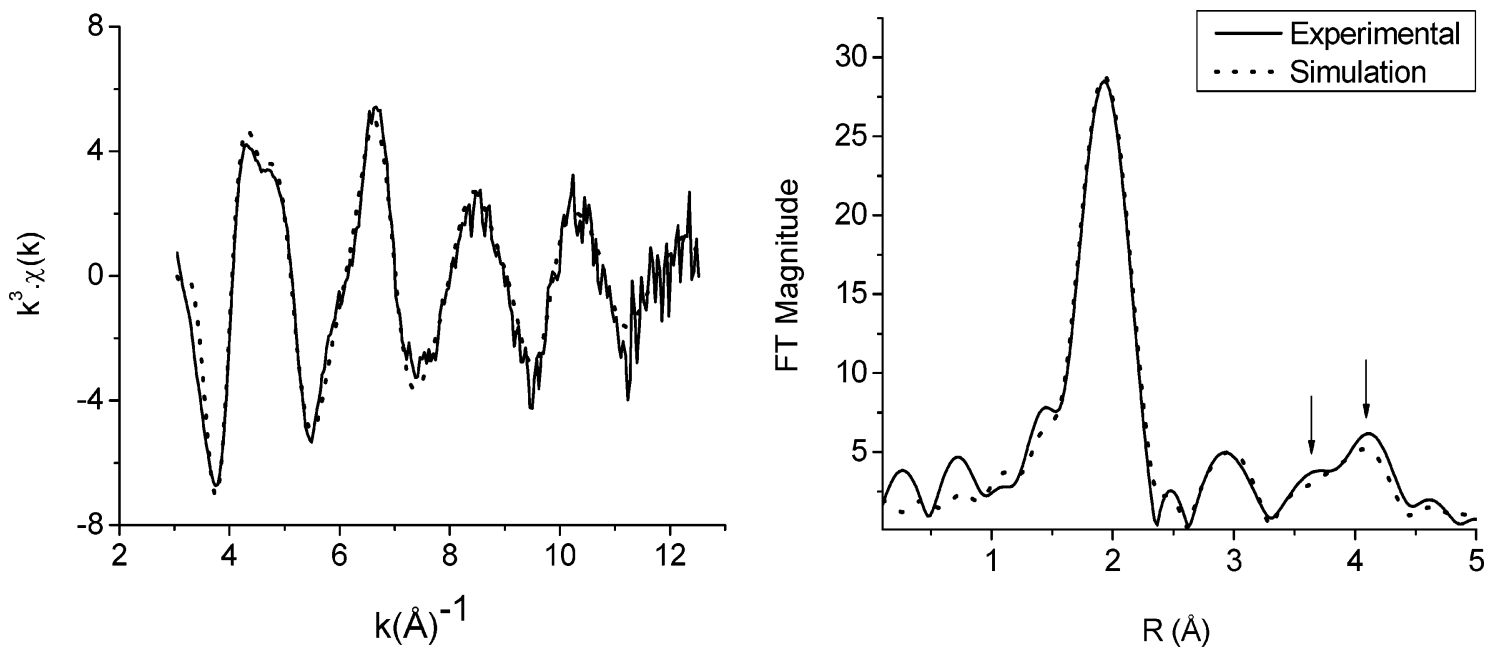

Figure 7. Full profile EXAFS fit and associated FT for the $\mathrm{Cu}\left(\mathrm{MIm}_{2} \mathrm{Pr}\right) \mathrm{ZY} 1$ sample. To fit the data, only two atom scattering paths needed to be included in the simulation, which would be consistent with a reduction of near neighbors contributing to multiple scattering. The down arrows highlight the areas in the FT where the simulation does not fit the experimental data very well. The cause of this mismatch is likely to be scattering from the zeolite framework, which was not included in the refinement.

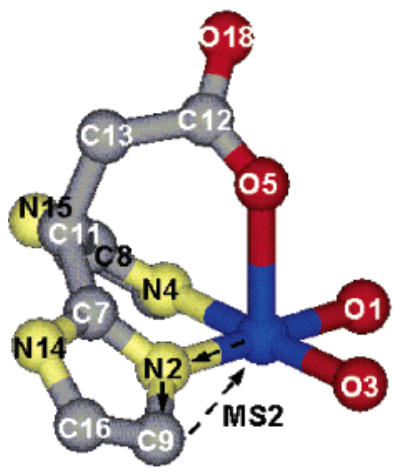

(a)

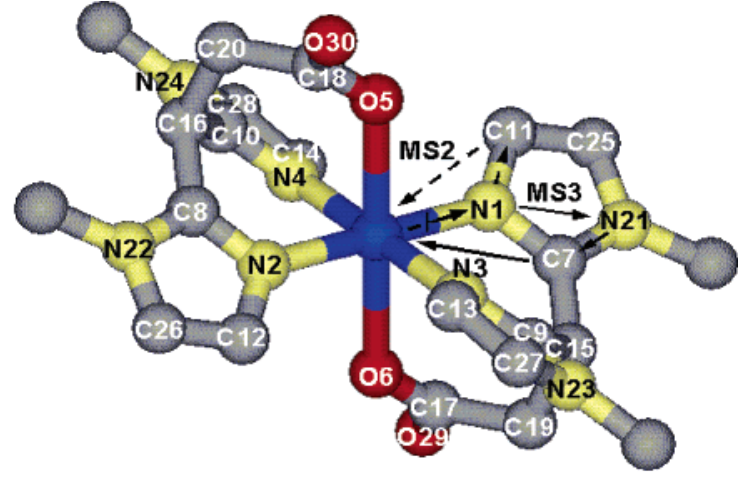

(b)

Figure 8. (a). Structure of the copper environment in $\mathrm{Cu}\left(\mathrm{MIm}_{2} \mathrm{Pr}\right) \mathrm{ZY} 1$ (species 1) as determined by whole profile EXAFS fitting using full cluster multiple scattering analysis procedures, where blue $=\mathrm{Cu}$, red $=\mathrm{O}$ (also atoms numbered $1,3,5$, and 18), yellow $=\mathrm{N}(2,4,14$, and 15$)$, gray $=\mathrm{C}(7-13,16$, and 17 although C10 and C17 are not labeled since they are obscured). (b) Structure of species 2. Also included are illustrations of the significant two-atom (dashed arrow and labeled MS2) and three-atom (full arrow and labeled MS3) multiple scattering pathways. In (a), the multiply scattered photoelectron follows the path $\mathrm{Cu}-\mathrm{N} 2-\mathrm{C} 9-\mathrm{Cu}$ in the MS2 case, whereas in (b), a similar MS2 path is illustrated $(\mathrm{Cu}-\mathrm{N} 1-\mathrm{C} 11-\mathrm{Cu})$ as well as an $\mathrm{MS} 3$ path $(\mathrm{Cu}-$ $\mathrm{N} 1-\mathrm{N} 21-\mathrm{C} 7-\mathrm{Cu}$ ). The bond distances for the numbered atoms are listed in Tables 4 and 5, respectively, whereas the significant multiple scattering pathways are listed in Tables A and B in the Supporting Information.

Table 6. Catalytic Performances of $\mathrm{Cu}\left(\mathrm{Mlm}{ }_{2} \mathrm{Pr}\right) \mathrm{ZY} 1$ and $\mathrm{Cu}\left(\mathrm{Mlm}_{2} \mathrm{Pr}\right)_{2}$ in the Benzyl Alcohol Oxidationa

\begin{tabular}{|c|c|c|c|c|c|c|}
\hline \multirow[b]{3}{*}{ catalyst } & \multicolumn{3}{|c|}{ Room temperature } & \multicolumn{3}{|c|}{$40^{\circ} \mathrm{C}$} \\
\hline & \multirow[b]{2}{*}{ TON $^{b}$} & \multicolumn{2}{|c|}{ product ratio (\%) } & \multirow[b]{2}{*}{ TON $^{b}$} & \multicolumn{2}{|c|}{ product ratio (\%) } \\
\hline & & benzaldehyde & benzoic acid & & benzaldehyde & benzoic acic \\
\hline $\mathrm{Cu}\left(\mathrm{MIm}_{2} \mathrm{Pr}\right) \mathrm{ZY} 1$ & 180 & 93 & 7 & 268 & 83 & 17 \\
\hline $\mathrm{Cu}\left(\mathrm{MIm}_{2} \mathrm{Pr}\right)_{2}$ & 32 & $>95$ & $<5$ & 346 & 80 & 20 \\
\hline
\end{tabular}

${ }^{a}$ Reaction time $=24 \mathrm{~h}, 2000$ equiv of substrate, and 3000 equiv of tert-butylhydroperoxide. ${ }^{b}$ TON $=$ turnover number, moles product/mol catalyst.

oxidation of benzyl alcohol at $60{ }^{\circ} \mathrm{C},{ }^{20}$ we tested our complexes for similar reactivity. The complexes were found to be active, and conversion of benzyl alcohol was achieved with $\mathrm{Cu}\left(\mathrm{MIm}_{2} \mathrm{Pr}\right) \mathrm{ZY} 1$ using tert-butylhydroperoxide as the oxidant. Interestingly, the complex was already active at room temperature, and a high product selectivity of $93 \%$ of benzaldehyde was observed (Table 6). The use of hydrogen peroxide did not result in oxidation of the substrate, instead catalase activity was found. When compared to the ([Cu(histidine $\left.\left.)_{2}\right] \mathrm{ZY}\right)$ system, $\mathrm{Cu}\left(\mathrm{MIm}_{2} \mathrm{Pr}\right) \mathrm{ZY} 1$ is more selective and active at lower temperature, albeit at considerably slower rate. A higher activity is observed at a temperature of $40{ }^{\circ} \mathrm{C}$, but with some loss of selectivity. At temperatures over $40{ }^{\circ} \mathrm{C}$, some leaching of the catalyst and concomitant coloring of the solution is seen, showing a limited stability of the complex under these reaction conditions. For comparison, the results obtained with the homogeneous, mononuclear species $\left[\mathrm{Cu}\left(\mathrm{MIm}_{2} \mathrm{Pr}\right)_{2}\right]$ are also included. At room temperature, the immobilized, five-coordinated copper complex is significantly faster than the coordinatively saturated homogeneous complex. At elevated temperature, the homogeneous complex is slightly faster, reflecting the more dynamic ligand exchange in solution at higher temperatures and 
possibly the limiting diffusion of the substrate into the zeolite superstructure.

\section{Discussion}

The present results show that we succeeded to isolate a mononuclear, one ligand complex utilizing the newly designed $\mathrm{MIm}_{2} \mathrm{Pr}$ ligand via immobilization inside a zeolite Y supercage. The novel heterogeneous compounds were characterized by several advanced spectroscopic techniques, and their molecular structure and catalytic activity could be compared with that of the homogeneous $\mathrm{Cu}\left(\mathrm{MIm}_{2} \mathrm{Pr}\right)_{2}$ system and $\mathrm{Cu}(\mathrm{His})$ complexes in zeolite Y.

According to our results, it is obvious that two different complexes, $\mathbf{1}$ and $\mathbf{2}$, are formed depending on the copper:ligand ratio. Table 3 summarizes the ESR and UV/vis features of species $\mathbf{1}$ and $\mathbf{2}$ in comparison with the homogeneous $\mathrm{Cu}\left(\mathrm{MIm}_{2} \mathrm{Pr}\right)_{2}$ complex and the zeolite-immobilized $\mathrm{Cu}$ (His) complexes A and B. Species $\mathbf{1}$ is formed in excess in the samples prepared with 1:1 metal-to-ligand ratio, whereas species 2 dominates in the samples prepared with 1:2 ratio. Species 1 stays inside the zeolite framework upon washing, while species $\mathbf{2}$ is easily washed out.

The UV/vis (Table 3), IR (Figure 4), and ESR (Figure 5) spectra indicate that the structure of complex $\mathbf{2}$ is the same as that of the $\mathrm{Cu}\left(\mathrm{MIm}_{2} \mathrm{Pr}\right)_{2}$ complex in solution. This complex is centrosymmetrical with four nitrogens in the equatorial plane around the copper ( $N N N N$-type coordination), whereas the two carboxylate oxygens are coordinating in axial positions. ${ }^{17}$ The two coordinating ligands make species 2 neutral and therefore difficult to stabilize within the pore system of the zeolite Y, which explains why it is easily washed out.

Species 1 remains in the zeolite supercage upon washing in the case of all of the prepared samples. Species $\mathbf{1}$ can only be formed via immobilization. It has no homogeneous counterpart, and therefore, its structure cannot be deduced by direct comparison with a homogeneous complex. Instead, comparisons can be made with similar compounds.

The shift from 590 to $690 \mathrm{~nm}$ in the d-d transitions of 2 and $\mathbf{1}$ indicates that $\mathbf{1}$ has a decreased ligand field splitting compared to 2 . This suggests that some of the nitrogen atoms surrounding the copper ion in species $\mathbf{2}$ are replaced by oxygen atoms. Indeed, the wavelength of the $d-d$ transitions in $\mathbf{1}$ (690 $\mathrm{nm}$ ) is very close to the wavelength of the $d-d$ transitions in complex $\mathrm{A}$ of $\mathrm{Cu}$ (His) in zeolite $\mathrm{Y}$, in which two nitrogen atoms are proposed to be coordinating to the copper cation. ${ }^{34}$ The decrease in $A_{\|}$value and increase in $g_{\|}$value when going from $\mathbf{2}$ to $\mathbf{1}$ (Table 3 ) indicate that some of the nitrogens present in $\mathbf{2}$ are replaced by oxygens in $\mathbf{1}$. Indeed, the 5-fold superhyperfine splitting pattern points toward the presence of two nitrogen atoms around the copper in $\mathbf{1}$. Comparison of the $A_{\|}$and $g_{\|}$ values in Table 3 suggest that the coordination environment in $\mathbf{1}$ is similar to that in complex $\mathrm{A}$ of $\mathrm{Cu}$ (His) in zeolite Y. A schematic representation of the coordination of the histidine ligands toward $\mathrm{Cu}^{2+}$ in the $\mathrm{Cu}$ (His) complexes $\mathrm{A}$ and $\mathrm{B}$ in zeolite $\mathrm{Y}$ is depicted in Figure 9.

EXAFS analysis confirms that the structure of species $\mathbf{1}$ is "half" of $\mathrm{Cu}\left(\mathrm{MIm}_{2} \mathrm{Pr}\right)_{2}$, that is, one of the ligands has been removed. The rest of the ligands around copper are oxygens, from the zeolite Y lattice and/or from a water molecule. Both the XANES and the EXAFS analyses reveal that there is a
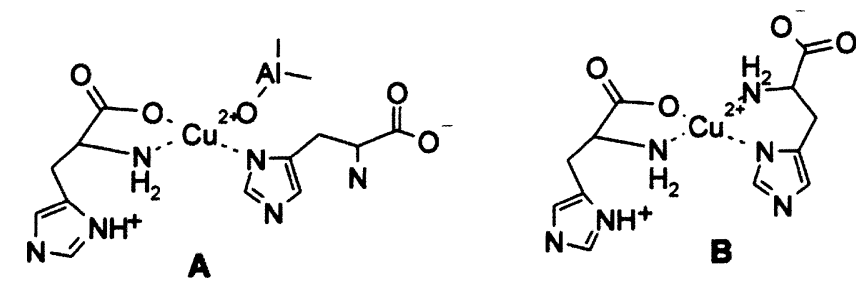

Figure 9. A schematic representation of the coordination of the histidine ligands toward $\mathrm{Cu}^{2+}$ in the $\mathrm{Cu}$ (His) complexes $\mathrm{A}$ and $\mathrm{B}$ in zeolite $\mathrm{Y} .{ }^{34}$

distorted 5-fold geometry around the central copper atom in species 1 . Thus, the spectroscopic data indicate that the structure of $\mathbf{2}$ is $\mathrm{Cu}\left(\mathrm{MIm}_{2} \mathrm{Pr}\right)_{2}$ and that $\mathbf{1}$ has a coordination sphere similar to encapsulated $\mathrm{Cu}(\mathrm{His})$ complex $\mathrm{A}$ with $\mathrm{NNO}$ OO-type coordination around copper. Species 1 with only one ligand has a charge +1 , and therefore, it is additionally stabilized inside the zeolite cage by the negative charge from the zeolite lattice. The structures of $\mathbf{1}$ and $\mathbf{2}$ are depicted in Figure 8.

Importantly, the catalytic results show that the immobilized species $\mathbf{1}$ is still accessible to substrate and oxidant and that it is catalytically active. Conversion of benzyl alcohol is already achieved at room temperature and with good selectivity. At room temperature, the species $\mathbf{1}$ showed a significantly higher activity than its mononuclear, homogeneous counterpart $\left[\mathrm{Cu}\left(\mathrm{MIm}{ }_{2} \mathrm{Pr}\right)_{2}\right]$. The lack of activity in the DTBC oxidation suggests that there are no available catalytic sites in which two copper atoms are in close enough proximity to facilitate binding of the substrate and mediate this reaction. These results therefore further corroborate the formulation of $\mathbf{1}$ as an isolated, mononuclear species that is coordinatively unsaturated.

\section{Conclusions}

In this study, a novel facial mononuclear $\mathrm{Cu}(\mathrm{II})$ complex $\mathbf{1}$, with one 2-His-1-carboxylate-type ligand coordinated to copper, was isolated by encapsulation inside a zeolite Y supercage. In the homogeneous system, depending on the stoichiometry, dinuclear or bis-ligand complexes prevail. In the immobilized system, a bis-ligand species $\mathbf{2}$, identical to the homogeneous $\mathrm{Cu}\left(\mathrm{MIm}_{2} \mathrm{Pr}\right)_{2}$, is also observed to form at higher (1:2) copper: ligand ratios. However, this complex is neutral and is therefore easily removed from the zeolite material upon washing. After washing, all of the prepared samples consist of species $\mathbf{1}$, independent of the initial copper precursor or the complex concentration.

Complex 1 catalyzes the oxidation of benzyl alcohol at room temperature with tert-butylhydroperoxide as the oxidant with good selectivity to benzaldehyde, displaying a higher activity compared to the homogeneous $\mathrm{Cu}\left(\mathrm{MIm}_{2} \mathrm{Pr}\right)_{2}$. Thus, immobilization inside the zeolite $\mathrm{Y}$ supercages proved to be an efficient method to isolate a mononuclear, monoligand complex $\mathbf{1}$ $\left[\mathrm{Cu}\left(\mathrm{MIm}_{2} \mathrm{Pr}\right)\right]$ with different catalytic properties, which cannot be stabilized as a homogeneous complex, thus demonstrating further the significant potential of using this synthetic approach to develop new catalytic materials. Endeavors to employ this strategy to mimic enzymes that contain the 2-His-1-carboxylate facial triad to arrive at new catalytic materials (based on, e.g., $\mathrm{Fe}^{2+}$ ) are currently ongoing in our laboratories.

Acknowledgment. The authors would like to thank the National Research School Combination-Catalysis (NRSC-C) for funding the project, Marijke Groothaert (Leuven University, 
Belgium) for help with the ESR measurements, Ad van der Eerden for the XRF measurements, Fouad Soulimani for help with the IR measurements, Sergey Nikitenko and Wim Bras (ESRF, BM26A) for help during the XAFS measurements, and the European Synchrotron Radiation Facility (Grenoble, France) for beam time.
Supporting Information Available: Further details regarding the EXAFS refinements, including a full profile fit of the $\mathrm{Cu}\left(\mathrm{MIm}_{2} \mathrm{Pr}\right)_{2}$ sample. This material is available free of charge via the Internet at http://pubs.acs.org.

JA0567992 